\title{
The Requirement of Business Model in Commercialization Research Products of Higher Education Institutions (HEIS):
}

\author{
Case study in Indonesia
}

\author{
Carolina M. Lasambouw ${ }^{1}$, Ediana Sutjiredjeki ${ }^{2, *}$, Neneng Nuryati ${ }^{1}$ \\ ${ }^{1}$ Accounting Department, ${ }^{2}$ Electrical Engineering Department \\ Politeknik Negeri Bandung \\ Bandung, Indonesia \\ carolina.magdalena@polban.ac.id, *ediana@polban.ac.id, neneng.nuryati@polban.ac.id
}

\begin{abstract}
This paper describes a business model (BM) requirement for research product commercialization within Indonesia HEIs. The objective is to determine the importance of $\mathrm{BM}$ as an assessment for research product commercialization feasibility. The study is conducted using a qualitative approach in selected 21 tertiary institutions in Indonesia comprised of nine universities and twelve polytechnics. Interviews and FGDs are carried out by involving the heads of related units for the commercialization process and senior researchers whose research results have been or ready to be commercialized. The questions posed are mainly related to the primitive elements for the commercialization process and the target market of the research product. All 21 institutions have developed various research products. Most of the products remain diverse, although leading HEIs focus on research products related to agricultural, medical and health, biopharma, IT and telecommunication, and education and training. In general, HEIs that have carried out research product commercialization has already prepared organizational management. Several research products in Indonesia are objected to appropriate technology; hence some HEIs conduct commercialization through community services activities. Unfortunately, none of the selected HEIs in this research have entirely answered the critical question for business model development. A good business model on each type of research product is still required to ease the gap between researchers and other stakeholders. Additionally, every researcher needs to provide a comprehensive research roadmap from the beginning so the research product end can be predicted earlier. Hence, the development of a good business model as a commercialization tool can be achieved.
\end{abstract}

Keywords-business model, research product commercialization, comprehensive research roadmap

\section{INTRODUCTION}

Institutions has long been encouraged to be carried out in many countries includes Indonesia, since it can boost national economic competitiveness. In the knowledge-based economics era, Higher Education Institutions (HEIs) role is becoming increasingly important. Universities or polytechnics become sources of ideas, knowledge, innovation, and technological advances. In Indonesia, the number of HEIs reached 4646 institutions, both public and private, referring to data from the Ministry of Research, Technology, and Higher Education; thus, Indonesia produces a considerable number of research outputs/products every year.

Research output (RO) is defined as the products generated from research, including proving the evidence, interpreting, and disseminating a research study's findings. The types of research output usually are very diverse. Identification of the types of research outcomes made concerning research outcomes that apply internationally, viz. Published papers, books, chapters, articles, processed data, patent, models, new plant varieties, community knowledge, consultancy reports, contract research, license, new drugs, a start-up company, technical reports, prototype, software application, education packages, short courses, training, workshops, sound/dialogue recording, member services, advocacy, governance, consulting, draft policy [1].

Moreover, in line with the knowledge-based economy era, various ROs can be generated into new products, processes, and or required systems to boost national economic competitiveness. Through the Ministry of Research and Technology, the Indonesian government continues to encourage and support higher education and R \& D institutions to produce more 'innovative products' with high added value than 'limited scientific publications'; instead. Innovation products are strongly supported, which can be marketed and benefit the community. Research products commercialization has become one of the government's critical agenda to boost economic growth in Indonesia. Therefore, universities and research institutes have to consider commercializing research products as one of their resources to generate incomes. Though not all innovation results are successful or can be 
commercialized. Consequently, the commercialization process of research results has not yet become the mainstream of various research institutions, especially for government-owned research institutes and universities. Therefore, the number of research results that have been successfully commercialized is still limited.

In principle, the commercialization of research products is no different from the commercialization of typical products; the difference is more difficult in practice, particularly academic research commercialization, which is very complex due to its broad diversity. Diversity of the research product, research outputs commercialization can be categorized into direct and indirect commercialization. Examples of research output that can be directly commercialized include patentable product and process, commercial software, etc. However, for ROs commercialization within a broader context, e.g., Knowledge Transfer Activities at a higher education institution, research output from social, human sciences, art, and others, indirect commercialization is required.

Most commercialization models are objected to be used only for research products resulted from engineering fields. The commercialization of research products is typically related to technology transfer activities from universities to technology users.

There are different strategies for research commercialization in the university, so each university or polytechnics has to find a strategy or a commercialization model that suits their mission. The selection of commercialization models becomes very crucial in order to succeed in marketing the research product. At the same time, Pellikka et al. [2] argue that the commercialization process's main difficulties relate to marketing, resources, the business environment, and the commercialization process is planning and management.

One of the critical points in commercializing innovative new technology or research products is designing an appropriate business model (BM). Chesbrough and Rosenbloom [2] defined that the business model can be an integrator between technology development and economic value creation. Furthermore, the term "business model" refers to the logic behind the commercialization process applied to realize the value of new technology products and how that value will be delivered to the customers. As Corkindale [3] believes that the commercialization of innovative new technology needs to be underpinned by an appropriate business model. The objective of this study is to identify the role of a $\mathrm{BM}$ in commercialization research products in HEIs of Indonesia and how elements of BM is defined will affect the collaboration between HEIs and other parties to succeed RO commercialization.

\section{RELATED WORKS}

Commercialization is not a simple process. It involves different elements and stakeholders: industry, university, researchers, legislation, society, and economy. In Indonesia, studies relating to examine the commercialization of technology in tertiary institutions have been conducted by [47]. Many approaches have been adopted, such as establishing the Intellectual Property Rights (IPR) office and setting a business incubator [4]. Moreover, the role of IPRs in the context of commercialization success is discussed by Asmoro [5]. While Sutopo et al. [6] explored funding sources available to support the growth of technology commercialization in university. A study about the most suitable strategy with a university spin-off company's development has been analyzed by Saputra et al. [7]. In addition to finding feasibility, commercialization [8] discussed metrics for research output commercialization in Indonesia. Then, confirmation of the Goldsmith model's commercialization model according to higher education researchers' perceptions in Indonesia has been carried out by Nuryati et al. [9]. While Lasambouw et al. [10] describes the importance of collaboration to support the commercialization of research outputs.

Most of the approaches have been implemented by Indonesia's leading universities such as the University of Indonesia (UI), University of Gajah Mada (UGM), Bogor Institute of Agriculture (IPB), Bandung Institute of Technology (ITB), University of Airlangga (UNAIR), and also private universities viz. Telkom University. While the rest of HEIs are still struggling to commercialize their research product. Even though technology transfer activities at Indonesian state universities do not appear to be very useful, with the limited collaboration between $\mathrm{HE}$ and industry in commercializing research products, it is still minimal [8]. Commercialization is a mechanism to transform the knowledge into products, services, and institutions by having a competitive advantage to achieve the regional economic growth do not appear significant attract industries to pay attention to technology and product resulted from the academic side. This condition may vary because of no transparent business model (BM). As Natsheh et al. [11] revealed, one of the factors that need to be considered during technology commercialization is a good business model.

Corkindale [3] has set out a way of operationalizing this general aim: "The business model is a useful framework to link technical decisions to economic outcomes. Further, he states that any organization seeking to commercialize a new technology needs a Business Model, which covers requirements of articulation the value created for users by the product or service containing the new technology. This including identification of the users to whom the product and the technology are useful and for what. Define the value chain, which is necessary to distribute and bring the product to the market, and stay there. The organization's revenue-generating mechanisms include the cost structure and (profit) margins of the product making, given the value chain assumptions, and formulation of the competitive strategy that will enable the organization to gain. Furthermore, maintain an advantage over rivals (or competing technologies).

Other scholars have also discussed the application of BM for commercializing innovative new technology [3]. Concept of Business Model Consulting Framework for Technology 
Commercialization of ICT SMEs also has been introduced [12]. Including BM for innovation commercialization process among small high-technology firms [2].

While Mets [13] has to create BM for commercialization of university research, and Flammini et al. [14] studied Business model configuration and dynamics for technology commercialization in mature markets,

Based on the previous literature reviews, it can be concluded that creating a good BM becomes imperative in order to minimize the failure of the commercialization of research products or innovation. However, because RO has a wide variety of range, BM's development for each research innovation might be particular and unique while maintaining the important elements of BM itself.

\section{MethodOLOGY}

A study of BM application for research output commercialization within 21 HEIs in Indonesia has been conducted in this research. The approach used in this research is an explorative- qualitative approach that is started by identifying the type of research products and the main activities to commercialize the innovation and or technology transfer process.

Information collection begins with a literature study to identify the types of research outcomes and aspects used in assessing research product results. In-depth exploration is carried out to find elements from each aspect and criteria to find. Interviews and focus group discussions were conducted with selected respondents purposively to confirm and complete the literature study results. The participants are the head and staff of the research division and community service and lecturers from 12 Polytechnics and 9 Universities.

The interview questions' focus is to explore knowledge about how universities face challenges in commercializing their academic community research outputs. Qualitative data collection was carried out through interviews and focus group discussions with leaders of research institutions from 21 universities and polytechnics. The focus is on universities that have implemented commercialization. To obtain valid data, the universities and polytechnics chosen to be visited must meet the following criteria:
- Excellence in research and development as evidenced by several patents, the number of academic publications and others,

- Excellent quality of research management shown by the research institute organization, and

- Good position in the national Higher Education Institution (HEI) ranking.

\section{FINDING AND DISCUSSION}

This research outlines various efforts undertaken by universities in Indonesia to increase the commercialization of research outputs. In order to find out how universities respond to the challenges of increasing the commercialization of their research output, interviews are conducted with the heads of research institutes and community service from twenty-one (21) tertiary institutions in Indonesia, consisting of nine (9) universities and twelve (12) polytechnics. The finding shows that not many university and polytechnic have commercialized their research products. However, most higher education keeps doing their best to increase their capability to commercialize their research products.

The interview questions' focus is to explore knowledge about how universities face challenges in commercializing their academic community research outputs. Qualitative data collection was carried out through interviews and focus group discussions with leaders of research institutions from 21 (twenty-one) universities, especially universities and polytechnics. The focus is on Universities that have implemented commercialization. The main questions posed are mainly questions relating to the primitive elements for the commercialization process [8], and one question relating to $\mathrm{BM}$ is 'What is the target market of your RO?'.

The data found through this FGD and interview are further grouped into four main sections, namely:

- Availability of research output product to commercialized

- Commercialization process

- Availability of transfer technology office, business incubator, teaching factory, and innovation center (organization readiness)

- Readiness for commercialization

The result found is depicted in Table 1 .

TABLE I. RESUlt FindiNGS OF RESEARCH OUTPUT COMMERCIALIZATION

\begin{tabular}{|l|c|c|c|c|c|c|c|c|}
\hline Result Finding & \multicolumn{2}{|c|}{$\begin{array}{c}\text { Availability of Research Product } \\
\text { to be Commercialized }\end{array}$} & \multicolumn{2}{|c|}{ Commercialization Process } & \multicolumn{2}{|c|}{ Organization readiness } & \multicolumn{2}{c|}{$\begin{array}{c}\text { Commercialization } \\
\text { Readiness }\end{array}$} \\
\hline & Ready & Not Ready & $\begin{array}{c}\text { Institutional } \\
\text { (Completed) }\end{array}$ & $\begin{array}{c}\text { Individual } \\
\text { (Not Clear) }\end{array}$ & Ready & $\begin{array}{c}\text { In } \\
\text { preparation }\end{array}$ & Ready & In progress \\
\hline University & $77.7 \%$ & $22.22 \%$ & $66.66 \%$ & $33.33 \%$ & $66.66 \%$ & $33.33 \%$ & $55.55 \%$ & $44.44 \%$ \\
\hline Polytechnic & $41.66 \%$ & $58.33 \%$ & $33.33 \%$ & $66.66 \%$ & $41.66 \%$ & $58.33 \%$ & $41.66 \%$ & $58.33 \%$ \\
\hline
\end{tabular}


All the 21 selected universities and polytechnics have already developed a lot of research output and products. The type of research products is varied, from academic published papers until innovation technology. Most of the products are still diverse, even though leading universities/polytechnics have focused on certain research products, such as agricultural, medical and health, biopharma, IT and telecommunication, and products for education training. In general, HEIs that have carried out research product commercialization has already prepared the organization management. In addition to Research and Community Services institutions, there are other divisions to implement these tasks viz. Transfer Technology Offices (TTO), Business Incubator. Research Product Gallery, Teaching Industry, and a company, particularly a start-up company.

Moreover, as a developing country, several research products in Indonesia are objected to appropriate technology. Hence some universities and polytechnics conduct research product commercialization through community services activities. The target is to empower local and or regional communities and to strengthen SMEs. Although there is no such direct commercialization, such activities may attract a government or industries that lead to a new government policy or funding to be invested in product manufacturing.

Based on the finding data, a collaboration between HEIs and other stakeholders must successfully succeed in a commercialization process, specifically with industry and investor. Some leading universities/polytechnics have also adopted this strategy, although the number is still too low compared to the number of HEIs in Indonesia. Unfortunately, none of the selected HEIs in this research completely answer the previous critical question for developing a business model. Even the idea about the availability of a good business model of each research product will boost commercialization and be socialized nationally.

\section{CONCLUSION}

Currently, the research is still in progress. The final research objective is to develop a model of Assessment for Commercialization Research Products Feasibility within Indonesia's HEIs. Although we have already found the metrics of commercialization elements, according to the

Finding data will be better if a profitable business model of each type of research product becomes one of the most critical points to be assessed to ease the gap between a researcher and other stakeholders. When the researcher develops a business model, there must be a specific division, e.g., TTO in each university/polytechnics. In addition to improving the quality of research product or innovation, every researcher has to provide a comprehensive research roadmap from the beginning. So the research product end might be predicted earlier; hence, developing a good business model as a commercialization tool can be achieved.

\section{ACKNOWLEDGMENT}

This research project is supported by funding from the Ministry of Research, Technology, and the Higher Education Republic of Indonesia under Fundamental National Competitive Research, Research Contract Number 135/SP2H/LT/DRPM/2019.

\section{REFERENCES}

[1] Directorate of Research and Community Services of the Ministry of Research, Technology and the Higher Education Republic of Indonesia, The Guide for Research and Community Services, 12th ed., 2019.

[2] J.T. Pellikka and P. Malinen, "Business models in the commercialization processes of innovation among small high-technology firms," Int. J. Innov. Technol. Manag., vol. 11, no. 02, p. 1450007, 2014

[3] D. Corkindale, "Towards a business model for commercializing innovative new technology," Int. J. Innov. Technol. Manag., vol. 7, no. 01, pp. 37-51, 2010.

[4] W. Dhewanto and K.K. Umam, "Technology Commercialisation in Indonesia: Current Condition and Its Challenges," Asian J. Technol. Manag., vol. 2, no. 1, pp. 1-13, 2009.

[5] P.K. Asmoro, "Technology Transfer in Indonesian State Universities Do IPRs Play a Significant Role,” Indon. L. Rev., vol. 7, p. 49, 2017.

[6] W. Sutopo, R.W. Astuti, and Y. Yuniaristanto, "The Schemes Funding Analyisis for Technology Commercialization: A Case Study,” J. Metris, vol. 18 , no. 1 , pp. 7-16, 2017.

[7] I.W. Saputra, W. Sutopo, and R. Zakaria, "A business strategy formulation for commercializing university-created technology: A university spin-offs," in AIP Conference Proceedings, 2018, vol. 1931, no. 1, p. 30020

[8] E. Sutjiredjeki, C.M. Lasambouw, and N. Nuryati, "Development of Metrics for Research Output Commercialization at Indonesia Higher Education Institutions," Proceedings of The International Conference on Advanced Research in Management, Economics and Accounting, 2019.

[9] N. Nuryati, C.M. Lasambouw, and E. Sutjiredjeki, "The Initial Model of Mathematics on Assessing Feasibility of Commercialization Higher Education Research Product in Indonesia," Proceeding of International Conference on Advanced Research in Management, Economics, and Accounting, 2019.

[10] C.M. Lasambouw, E. Sutjiredjeki, and N. Nuryati, "Collaboration to Support the Commercialization of Polytechnic Research Products in Indonesia: Potential and Challenges," Proceeding of International Conference on Advanced Research in Management, Economics, and Accounting.

[11] A. Al Natsheh, S.A. Gbadegeshin, A. Rimpiläinen, I. Imamovic-Tokalic and A. Zambrano, "Identifying the challenges in commercializing high technology: A case study of quantum key distribution technology,' Technol. Innov. Manag. Rev., vol. 5, no. 1, 2015.

[12] J.C. Lee, J.-W. Hong, and S.K. Lee, "A Study on Business Model Consulting Framework for Technology Commercialization of ICT SMEs," Indian J. Sci. Technol., vol. 9, no. 26, pp. 1-9, 2016

[13] T. Mets, "Creating business model for commercialization of university research," Organ. Vadyb. Sist. Tyrim., no. 51, pp. 83-94, 2009.

[14] S. Flammini, G. Arcese, M.C. Lucchetti, and L. Mortara, "Business model configuration and dynamics for technology commercialization in mature markets,” Br. Food J., 2017. 